\title{
CT-based thermometry with virtual monoenergetic images by dual-energy of fat, muscle and bone using FBP, iterative and deep learning-based reconstruction
}

\author{
Andreas Heinrich $^{1}$ (D) $\cdot$ Sebastian Schenkl ${ }^{2}$ - David Buckreus ${ }^{1} \cdot$ Felix V. Güttler $^{1}$ • Ulf K-M. Teichgräber ${ }^{1}$
}

Received: 28 May 2021 / Accepted: 7 July 2021 / Published online: 29 July 2021

(C) The Author(s) 2021

\begin{abstract}
Objectives The aim of this study was to evaluate the sensitivity of CT-based thermometry for clinical applications regarding a three-component tissue phantom of fat, muscle and bone. Virtual monoenergetic images (VMI) by dual-energy measurements and conventional polychromatic $120-\mathrm{kVp}$ images with modern reconstruction algorithms adaptive statistical iterative reconstruction-Volume (ASIR-V) and deep learning image reconstruction (DLIR) were compared.

Methods A temperature-regulating water circuit system was developed for the systematic evaluation of the correlation between temperature and Hounsfield units (HU). The measurements were performed on a Revolution CT with gemstone spectral imaging technology (GSI). Complementary measurements were performed without GSI (voltage $120 \mathrm{kVp}$, current 130-545 mA). The measured object was a tissue equivalent phantom in a temperature range of 18 to $50^{\circ} \mathrm{C}$. The evaluation was carried out for VMI at 40 to $140 \mathrm{keV}$ and polychromatic $120-\mathrm{kVp}$ images.

Results The regression analysis showed a significant inverse linear dependency between temperature and average HU regardless of ASIR-V and DLIR. VMI show a higher temperature sensitivity compared to polychromatic images. The temperature sensitivities were $1.25 \mathrm{HU} /{ }^{\circ} \mathrm{C}(120 \mathrm{kVp})$ and $1.35 \mathrm{HU} /{ }^{\circ} \mathrm{C}(\mathrm{VMI}$ at $140 \mathrm{keV})$ for fat, $0.38 \mathrm{HU} /{ }^{\circ} \mathrm{C}(120 \mathrm{kVp})$ and $0.47 \mathrm{HU} /{ }^{\circ} \mathrm{C}(\mathrm{VMI}$ at $40 \mathrm{keV})$ for muscle and $1.15 \mathrm{HU} /{ }^{\circ} \mathrm{C}(120 \mathrm{kVp})$ and $3.58 \mathrm{HU} /{ }^{\circ} \mathrm{C}(\mathrm{VMI}$ at $50 \mathrm{keV})$ for bone.

Conclusions Dual-energy with VMI enables a higher temperature sensitivity for fat, muscle and bone. The reconstruction with ASIR-V and DLIR has no significant influence on CT-based thermometry, which opens up the potential of drastic dose reductions.

Key Points

- Virtual monoenergetic images (VMI) enable a higher temperature sensitivity for fat (8\%), muscle (24\%) and bone (211\%) compared to conventional polychromatic 120-kVp images.

- With VMI, there are parameters, e.g. monoenergy and reconstruction kernel, to modulate the temperature sensitivity. In contrast, there are no parameters to influence the temperature sensitivity for conventional polychromatic 120-kVp images.

- The application of adaptive statistical iterative reconstruction-Volume (ASIR-V) and deep learning-based image reconstruction (DLIR) has no effect on CT-based thermometry, opening up the potential of drastic dose reductions in clinical applications.
\end{abstract}

Keywords Computed tomography $\cdot$ Thermometry $\cdot$ Dual-energy scanned projection $\cdot$ Deep learning

Andreas Heinrich

andreas.heinrich@med.uni-jena.de

1 Department of Radiology, Jena University Hospital - Friedrich Schiller University, Am Klinikum 1, 07747 Jena, Germany

2 Institute of Forensic Medicine, Jena University Hospital - Friedrich Schiller University, Am Klinikum 1, 07747 Jena, Germany
Abbreviations

ASIR-V Adaptive statistical iterative reconstructionVolume

CI Confidence interval

DLIR Deep learning image reconstruction

FBP Filtered back projection

GSI Gemstone spectral imaging

VMI Virtual monoenergetic images 


\section{Introduction}

Radiodensity depends on the temperature of the tissue, since the density decreases if the temperature of the tissue increases. The changes in tissue temperature can therefore be measured indirectly via the computed tomography (CT) numbers or Hounsfield units (HU), also called CTbased thermometry. However, the sensitivity (change of $\mathrm{HU}$ per ${ }^{\circ} \mathrm{C}$ ) depends on the volumetric thermal expansion coefficient of the specific material [1]. The temperature sensitivity was reported to range between -0.40 and $-0.29 \mathrm{HU} /{ }^{\circ} \mathrm{C}$ for water [1], between -0.52 and -0.60 $\mathrm{HU} /{ }^{\circ} \mathrm{C}$ for porcine liver $[2,3]$, and between -0.45 and $-0.43 \mathrm{HU} /{ }^{\circ} \mathrm{C}$ for muscle $[4,5]$. Possible applications of CT-based thermometry would be the monitoring of tissue temperatures during high-frequency treatments or microwave ablation of tumors in the liver and kidneys [2, 3, 6-9]. Despite these clear relationships, the method is rarely used in clinical practice so far [10], because the repeatability of quantitative $\mathrm{CT}$ numerical measurements has not been guaranteed and a higher required ionizing radiation, e.g. for thermometry due to more frequent scans [11]. Further research is required to systematically analyze the influencing factors on CT-based thermometry [12, 13], so as demonstrate if better levels of thermal-spatial resolution could be achieved, along with lower patient radiation doses [1]. With recent technical advances in CT (Fig. 1), such as dual-energy and iterative reconstruction, e.g. adaptive statistical iterative reconstruction-Volume (ASIR-V) [14, 15], or deep learning image reconstruction (DLIR) [16], the question arises whether these advances have improved the quality of CT-based thermometry. DLIR represents the latest stage of development in CT image reconstruction and promises significant improvements in image quality and radiation dose reduction compared to ASIR-V and filtered back projection (FBP) [16-18]. A dual-energy CT with a gemstone spectral imaging (GSI) detector measures the raw data of an object during a continuous energy change between low $(80 \mathrm{kVp})$ and high $(140 \mathrm{kVp})$ voltage [19]. This generates two data records with different attenuation values based on the corresponding energy levels, which allow the reconstruction of material decomposition images and virtual monoenergetic images (VMI). VMI demonstrated significantly better signal-to-noise ratio (SNR), contrast-to-noise ratio (CNR) and subjective score compared to conventional $120-\mathrm{kVp}$ polychromatic images [20].

The objective of this study was to evaluate CT-based thermometry for fat, muscle and bone using state-of-the-art imaging technology. This includes the dose reduction potential of modern reconstruction algorithms with ASIR-V and DLIR, and the use of VMI at $40-140 \mathrm{keV}$ versus conventional polychromatic $120-\mathrm{kVp}$ images.

\section{Materials and methods}

The measured object was a tissue-equivalent phantom [21, 22], composed of beeswax (density $0.95 \mathrm{~g} / \mathrm{cm}^{3}$, fat-equivalent), salt-water solution (density $1.04 \mathrm{~g} / \mathrm{cm}^{3}$, muscle-equivalent) and a bovine femoral bone (density $1.36 \mathrm{~g} / \mathrm{cm}^{3}$ ). The phantom (length $19.40 \mathrm{~cm}$, width $17.20-17.40 \mathrm{~cm}$ and height $15.20 \mathrm{~cm}$ ) was placed into a separate phantom container (length $39.00 \mathrm{~cm}$, width $32.00 \mathrm{~cm}$ and height $30.50 \mathrm{~cm}$ ) and fastened.

\section{Temperature regulation}

A temperature-regulating water circuit system (Fig. 2) was developed for the systematic evaluation of the correlation of temperature and CT number. More than $35 \mathrm{~L}$ of water was heated in a water bath (Thermoboy c20, mgw Lauda) and subsequently pumped through a silicone hose into the phantom housing container. The phantom container features an overflow port located above the top edge of the phantom. Consequently, it is guaranteed that the phantom is completely immersed by water. When it reaches the overflow port, the water flows back into the water bath basin. This measurement setup constitutes a closed system; thus, the temperature can be kept constant over a long period of time. The temperature of the system was monitored by four T1 fiber-optic temperature probes (Rugged Fiber Optic Temperature Monitoring System). In the top center of the phantom is a 7.50-cm-deep blind hole that accommodates a temperature probe (probe 1) for monitoring the phantom's core temperature. Another temperature probe (probe 2) is located on the side at a depth of $2 \mathrm{~cm}$ in the phantom. To avoid the risk of water infiltrating and thus distorting the temperature measurement, both holes were sealed with beeswax. Two additional temperature probes were located directly in the water in the phantom housing tank (probe 3) and in the water bath (probe 4).

\section{CT measurements and evaluation}

The measurements were performed in a temperature range from 18 up to $50^{\circ} \mathrm{C}$ (step size approx. $5^{\circ} \mathrm{C}$ ) on a Revolution CT (GE Healthcare) by means of the GSI technology (voltage $80 \mathrm{kV}$ and $140 \mathrm{kV}$, current 235-360 mA SmartmA, helical scan type, pitch 0.992). Complementary measurements were performed without GSI (voltage $120 \mathrm{kV}$, current 130-545 $\mathrm{mA}$, helical scan type, pitch 0.992). Measurements were repeated $(n=14)$ for each temperature and CT protocol. To increase the reliability, the measurements were performed in thermodynamic equilibrium of the phantom. This required a waiting time of 4 to $10 \mathrm{~h}$ between measurements.

The raw data were reconstructed by FBP (= ASIR-V 0\%), ASIR-V $(50 \%, 100 \%)$ and DLIR-L (lowest filtering), DLIR- 


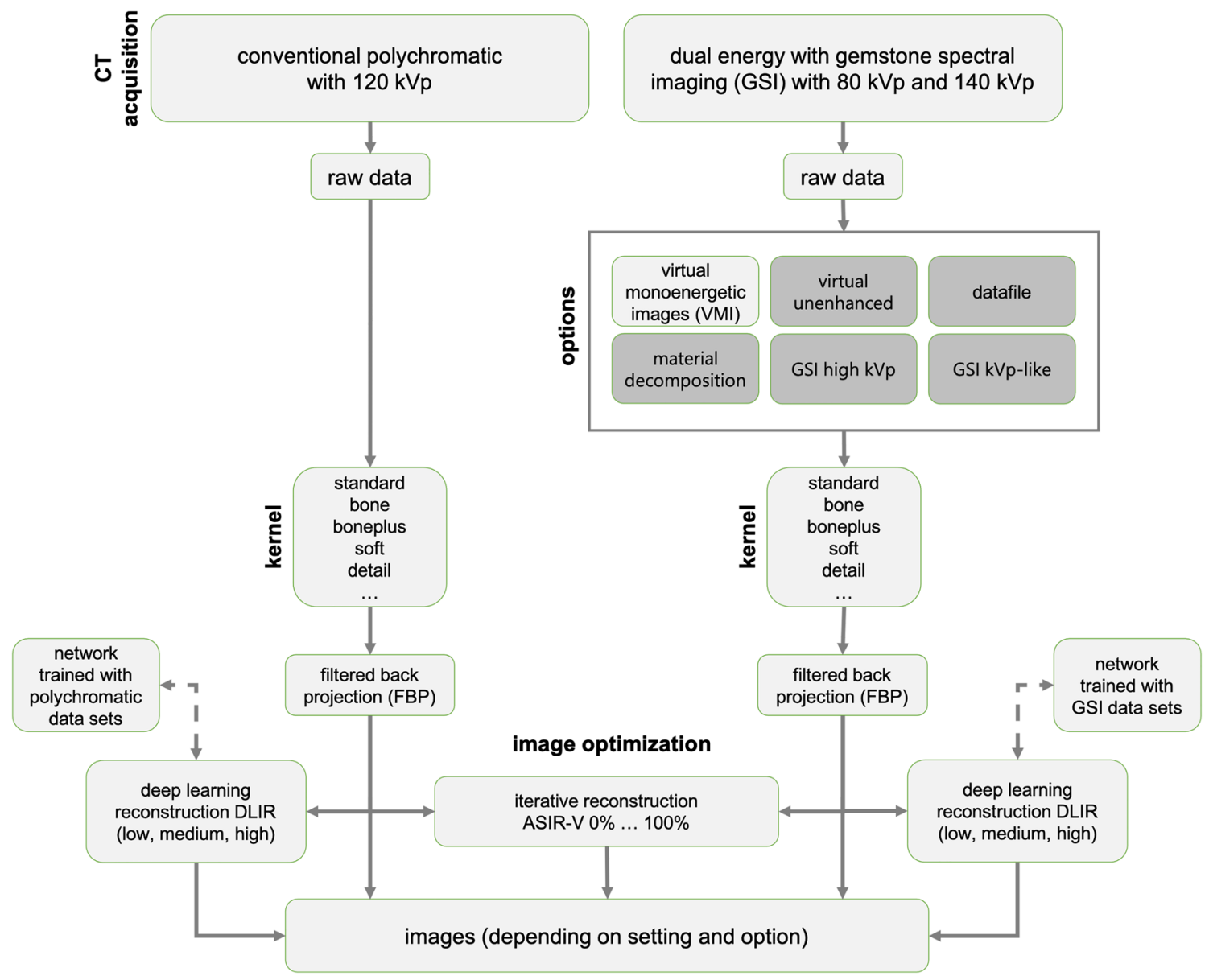

Fig. 1 Scheme of data acquisition and image reconstruction in the CT.

$\mathrm{M}$ (medium filtering) and DLIR-H (highest filtering) with the standard kernel and an image matrix of $512 \times 512$ pixels. For the evaluation of the GSI raw data, VMI at $40 \mathrm{keV}, 50 \mathrm{keV}, 60$ $\mathrm{keV}, 70 \mathrm{keV}, 80 \mathrm{keV}, 100 \mathrm{keV}, 120 \mathrm{keV}$ and $140 \mathrm{keV}$ were used. Additionally, the kernels bone, boneplus, soft and detail were examined for polychromatic images and GSI (VMI at 40 $\mathrm{keV}, 70 \mathrm{keV}$ and $120 \mathrm{keV}$ ) with ASIR-V 100\%. The standard kernel had to be used for DLIR.
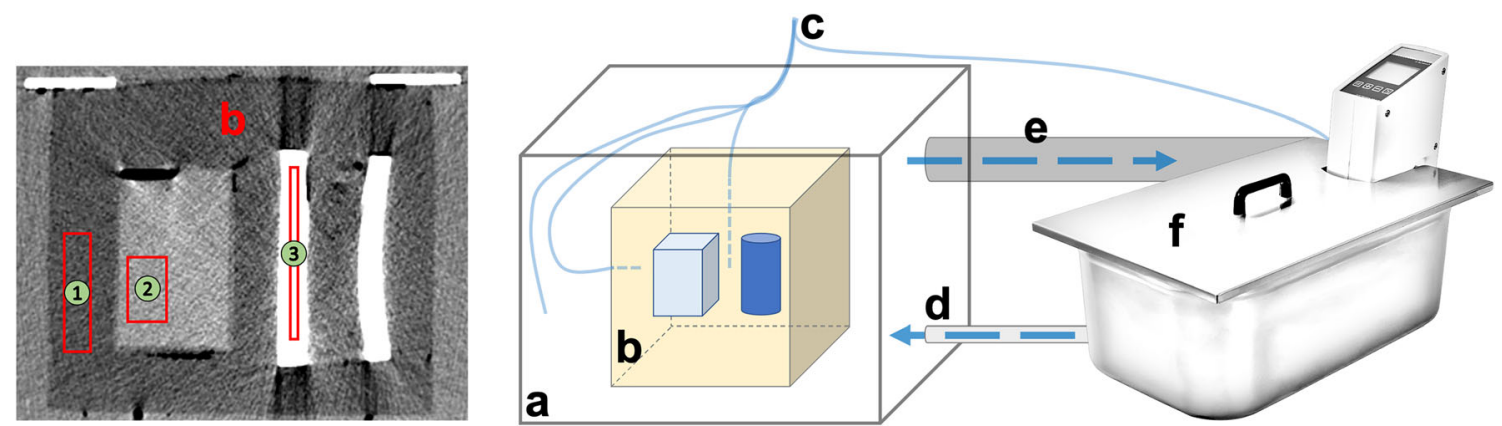

Fig. 2 Left virtual monoenergetic image (VMI) at $70 \mathrm{keV}$ of the tissueequivalent phantom with rectangle regions of interest (ROIs) for measurement of fat-equivalent (beeswax, 1), muscle-equivalent (salty water solution, 2) and bovine bone (3). Right temperature-regulating water circuit system with (a) phantom housing container with fixture for the (b) tissueequivalent phantom and (c) temperature probes. Water is pumped into the phantom housing container through (d) a silicone hose, (e) an overflow pipe returning the water back into the (f) water bath with heater $(0-100$ ${ }^{\circ} \mathrm{C}$ ) and pump. During a series of measurements, the phantom container and the water bath were covered by lids so that the system constituted a closed circuit. 
For each measurement, the average HU of rectangle regions of interest (ROIs) with mean areas of $8.24 \mathrm{~cm}^{2}$ for fat $(25 \times 96$ pixels $)$ and muscle $(40 \times 60$ pixels $)$ and $2.58 \mathrm{~cm}^{2}$ for bone $(5 \times 150$ pixels $)$ was analyzed (Fig. 2 left). The ROIs were set automatically; thus, the position of the ROIs was exactly at the same position for all reconstructions. The dependency of the average CT numbers as a function of temperature was analyzed using linear regression analysis. The software SPSS Statistics, version 26 (IBM), was used for statistical evaluation. The $95 \%$ and $50 \%$ confidence intervals (CI) were calculated for the temperature sensitivity.

\section{Results}

The measurement setup enabled reproducible measurements. During the measuring process, no movement artefacts caused by the circulating water system were observed (Fig. 3). The bone, in parts, showed beam hardening artefacts. The measurement uncertainty due to temperature gradients between the margin of the phantom and the core center was $0.59 \pm$ $0.37^{\circ} \mathrm{C}$ (temperature probes 1 and 2). The difference between water temperatures in the water bath and phantom housing container was $0.37 \pm 0.28^{\circ} \mathrm{C}$ (temperature probes 3 and 4).

The regression analysis showed a significant inverse linear dependency between temperature and average CT number (Fig. 4 left). Depending on the monoenergy, the
VMI show a higher temperature sensitivity compared to polychromatic images (Fig. 4 right). For fat, the temperature sensitivities were $1.25 \mathrm{HU} /{ }^{\circ} \mathrm{C}(95 \% \mathrm{CI} 1.18-1.33)$ for $120 \mathrm{kVp}, 1.19 \mathrm{HU} /{ }^{\circ} \mathrm{C}(95 \%$ CI $1.08-1.31)$ for $\mathrm{VMI}$ at $40 \mathrm{keV}$ and $1.35 \mathrm{HU} /{ }^{\circ} \mathrm{C}(95 \% \mathrm{CI} 1.27-1.42)$ for $\mathrm{VMI}$ at $140 \mathrm{keV}$. For muscle, the temperature sensitivities were $0.38 \mathrm{HU} /{ }^{\circ} \mathrm{C}(95 \% \mathrm{CI} 0.34-0.42)$ for $120 \mathrm{kVp}, 0.47 \mathrm{HU} /$ ${ }^{\circ} \mathrm{C}$ (95\% CI $\left.0.34-0.59\right)$ for VMI at $40 \mathrm{keV}$ and $0.37 \mathrm{HU} /$ ${ }^{\circ} \mathrm{C}$ (95\% CI $\left.0.33-0.42\right)$ for VMI at $140 \mathrm{keV}$. For bone, the temperature sensitivities were $1.15 \mathrm{HU} /{ }^{\circ} \mathrm{C}(95 \% \mathrm{CI}$ $0.87-1.43)$ for $120 \mathrm{kVp}, 3.58 \mathrm{HU} /{ }^{\circ} \mathrm{C}(95 \% \mathrm{CI} 3.07-$ 4.09) for $\mathrm{VMI}$ at $50 \mathrm{keV}$ and $0.35 \mathrm{HU} /{ }^{\circ} \mathrm{C}(95 \% \mathrm{CI}$ $0.20-0.49$ ) for VMI at $140 \mathrm{keV}$.

The application of ASIR-V and DLIR had no significant impact on the temperature sensitivity (Fig. 5 left). The reconstruction kernel has no effect on conventional polychromatic $120-\mathrm{kVp}$ measurements (max difference $0.01 \mathrm{HU} /{ }^{\circ} \mathrm{C}$ ); however, it can affect the temperature sensitivity for VMI (Fig. 5 right). For fat, the temperature sensitivity varies between $0.01 \mathrm{HU} /{ }^{\circ} \mathrm{C}(\mathrm{VMI}$ at $70 \mathrm{keV}$ ) and $0.08 \mathrm{HU} /{ }^{\circ} \mathrm{C}$ (VMI at $40 \mathrm{keV}$ : standard $1.19 \mathrm{HU} /{ }^{\circ} \mathrm{C}$, bone $1.15 \mathrm{HU} /{ }^{\circ} \mathrm{C}$, boneplus $1.15 \mathrm{HU} /{ }^{\circ} \mathrm{C}$, soft $1.17 \mathrm{HU} /$ ${ }^{\circ} \mathrm{C}$, detail $1.23 \mathrm{HU} /{ }^{\circ} \mathrm{C}$; VMI at $120 \mathrm{keV}$ : standard 1.34 $\mathrm{HU} /{ }^{\circ} \mathrm{C}$, bone $1.36 \mathrm{HU} /{ }^{\circ} \mathrm{C}$, boneplus $1.36 \mathrm{HU} /{ }^{\circ} \mathrm{C}$, soft $1.35 \mathrm{HU} /{ }^{\circ} \mathrm{C}$, detail $1.33 \mathrm{HU} /{ }^{\circ} \mathrm{C}$ ). For muscle, compared to the standard kernel, only the bone kernel has a negative influence on the temperature sensitivity (VMI at $40 \mathrm{keV}$ :

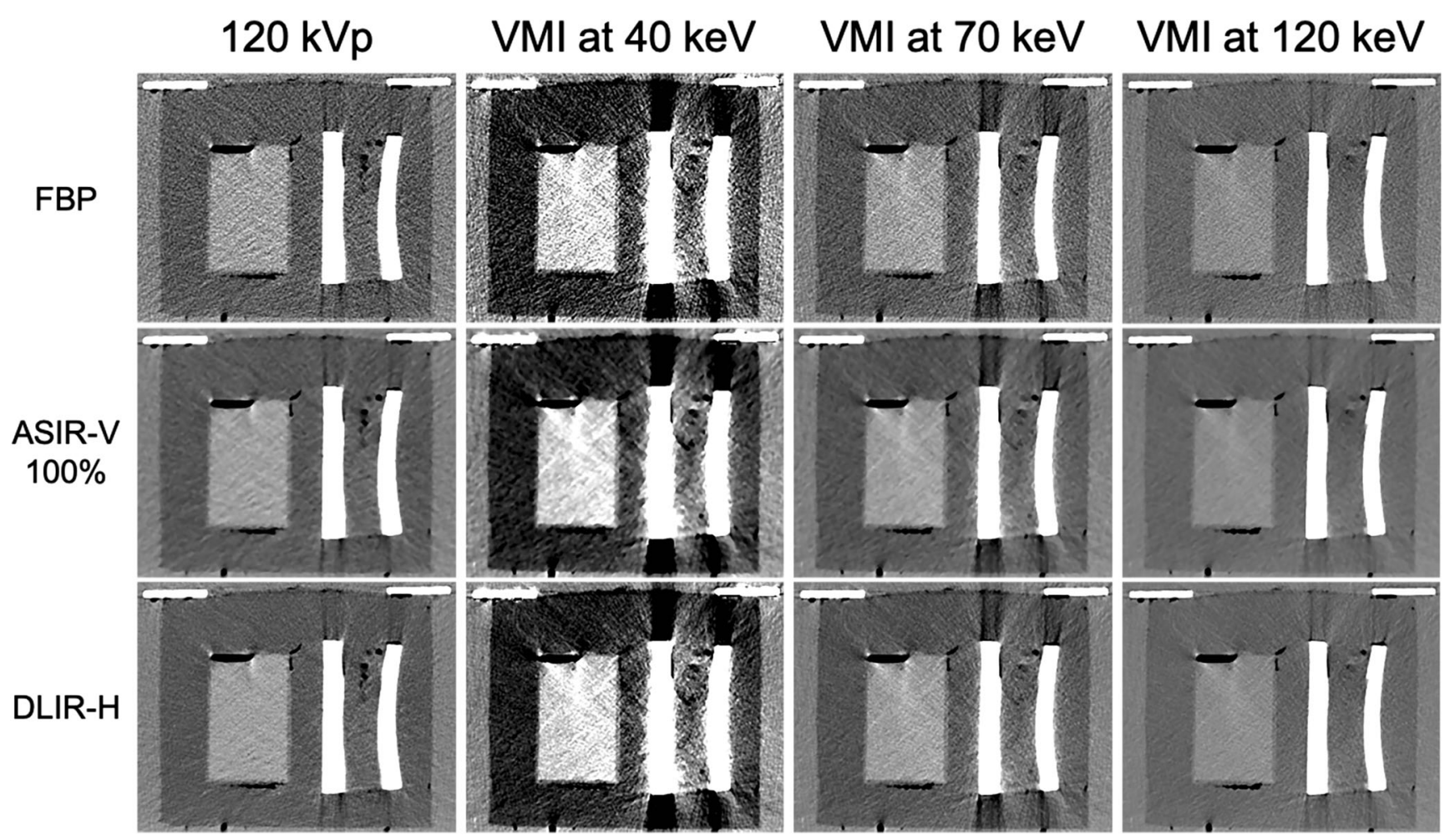

Fig. 3 Polychromatic 120-kVp images and virtual monoenergetic images (VMI) with three types of reconstruction (FBP, ASIR-V 100\%, DLIR-H) are shown. 

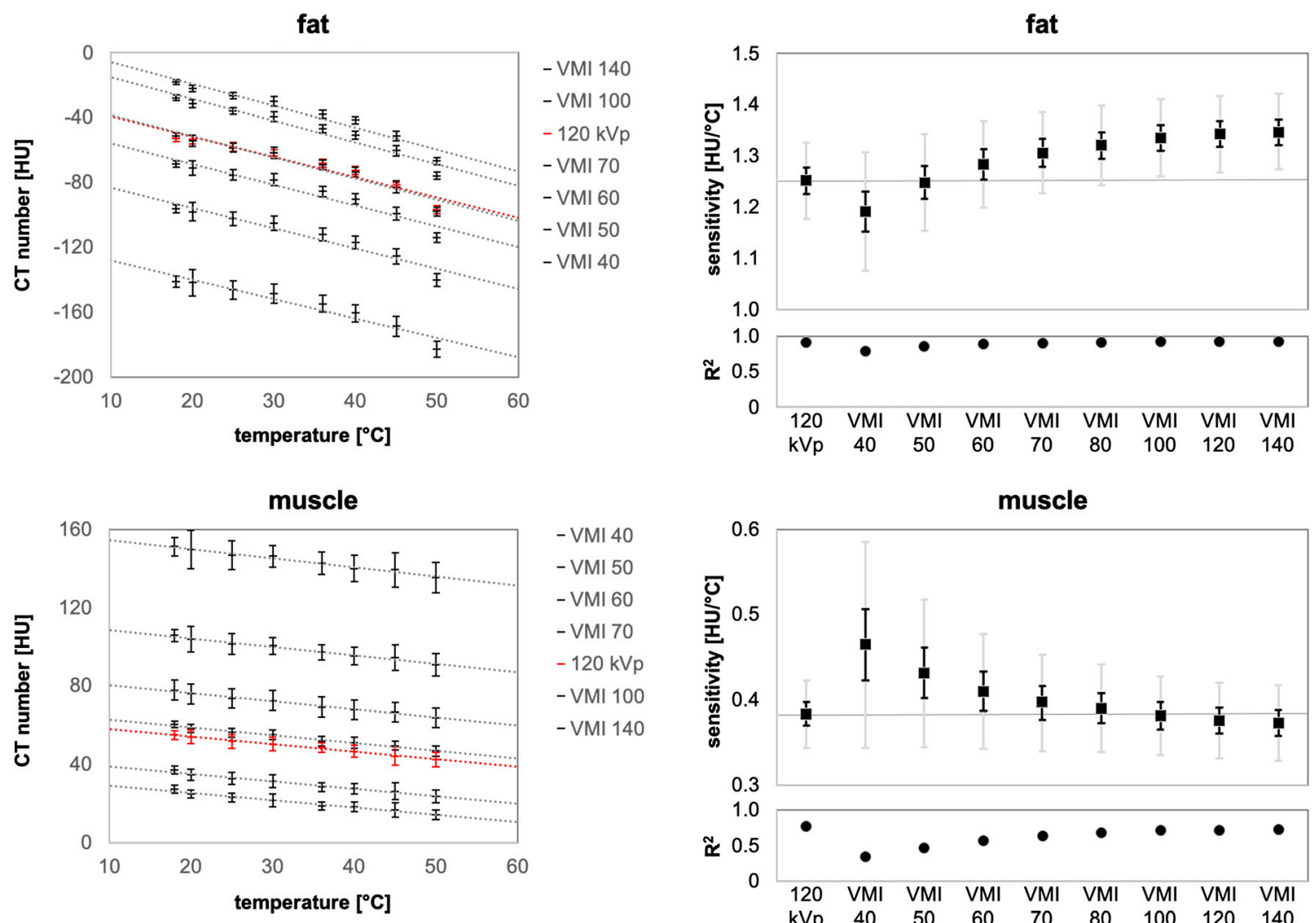

- VMI 40

- VMI 50

- VMI 60

- VMI 70

$-120 \mathrm{kVp}$

- VMI 100

- VMI 140
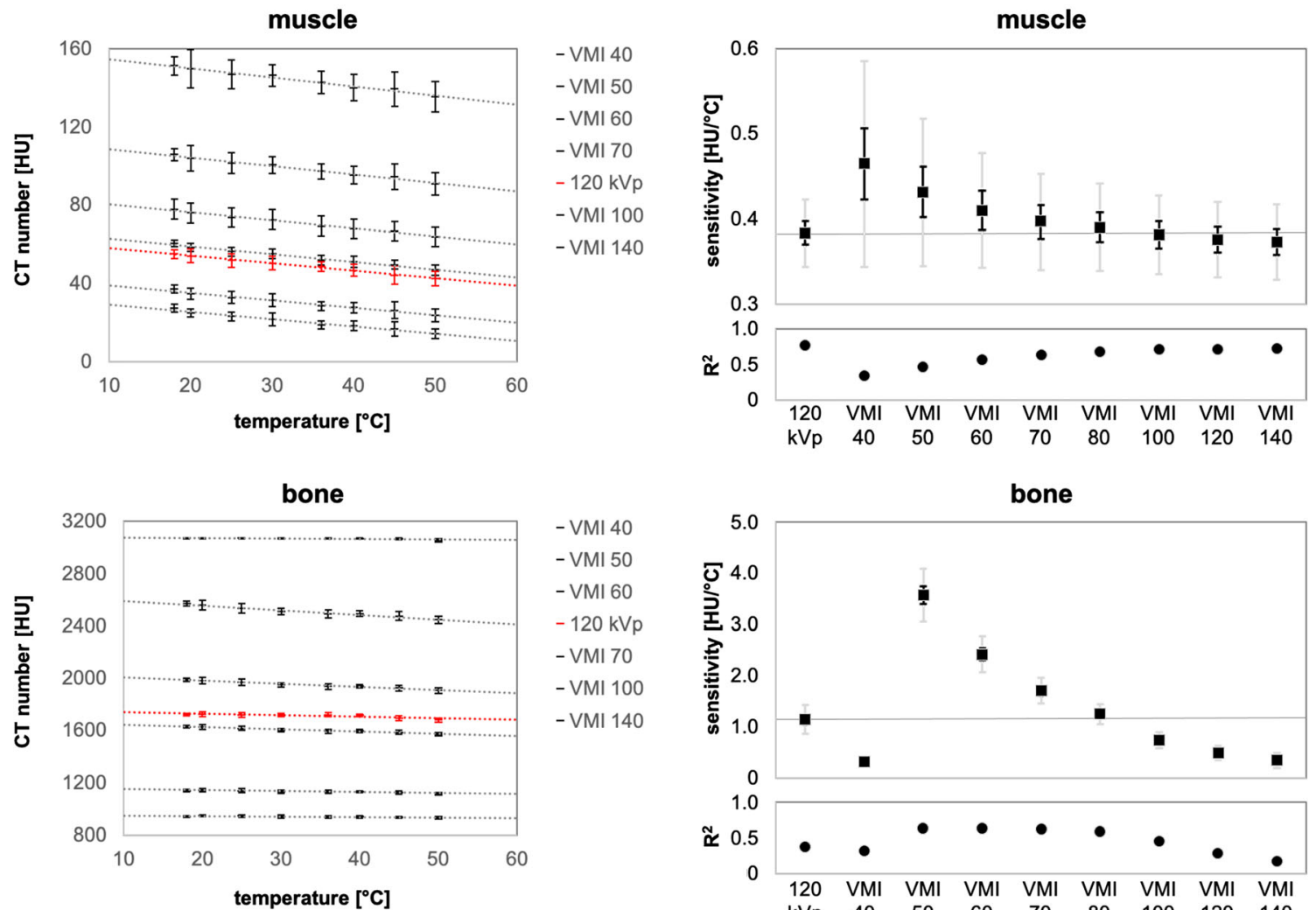

- VMI 40

- VMI 50

- VMI 60

$-120 \mathrm{kVp}$

- VMI 70

- VMI 100

-VMI 140

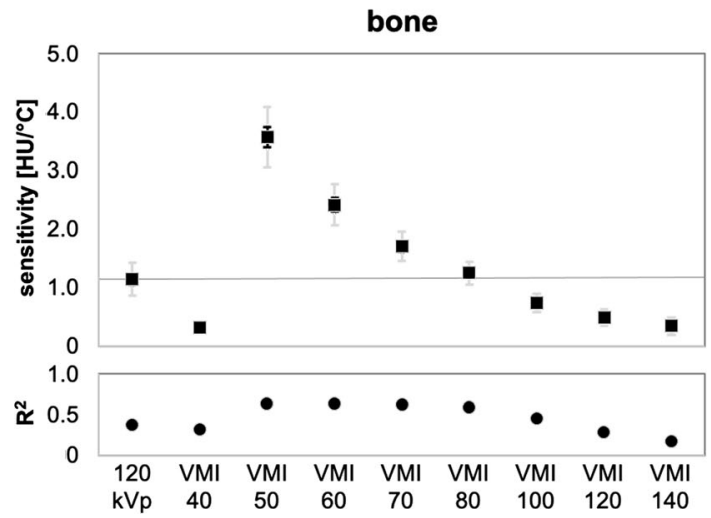

Fig. 4 Left dependency of the CT number on the temperature with linear regression analysis for virtual monoenergetic images (VMI) and polychromatic $120-\mathrm{kVp}$ images. Right results of temperature sensitivity with

standard $0.47 \mathrm{HU} /{ }^{\circ} \mathrm{C}$, bone $0.39 \mathrm{HU} /{ }^{\circ} \mathrm{C}$, boneplus 0.38 $\mathrm{HU} /{ }^{\circ} \mathrm{C}$; VMI at $70 \mathrm{keV}$ : standard $0.40 \mathrm{HU} /{ }^{\circ} \mathrm{C}$, bone $0.37 \mathrm{HU} /{ }^{\circ} \mathrm{C}$, boneplus $0.37 \mathrm{HU} /{ }^{\circ} \mathrm{C}$; VMI at $120 \mathrm{keV}$ : standard $0.38 \mathrm{HU} /{ }^{\circ} \mathrm{C}$, bone $0.37 \mathrm{HU} /{ }^{\circ} \mathrm{C}$, boneplus 0.37 $\mathrm{HU} /{ }^{\circ} \mathrm{C}$ ). In contrast, the bone kernel may have advantages for representation of bones (VMI at $40 \mathrm{keV}$ : standard 0.31 $\mathrm{HU} /{ }^{\circ} \mathrm{C}$, bone $0.51 \mathrm{HU} /{ }^{\circ} \mathrm{C}$, boneplus $0.94 \mathrm{HU} /{ }^{\circ} \mathrm{C}$, soft $0.30 \mathrm{HU} /{ }^{\circ} \mathrm{C}$, detail $0.37 \mathrm{HU} /{ }^{\circ} \mathrm{C}$; VMI at $70 \mathrm{keV}$ : standard $1.72 \mathrm{HU} /{ }^{\circ} \mathrm{C}$, bone $1.60 \mathrm{HU} /{ }^{\circ} \mathrm{C}$, boneplus $1.67 \mathrm{HU} /{ }^{\circ} \mathrm{C}$, soft $1.74 \mathrm{HU} /{ }^{\circ} \mathrm{C}$, detail $1.70 \mathrm{HU} /{ }^{\circ} \mathrm{C}$; VMI at $120 \mathrm{keV}$ : standard $0.51 \mathrm{HU} /{ }^{\circ} \mathrm{C}$, bone $0.55 \mathrm{HU} /{ }^{\circ} \mathrm{C}$, boneplus 0.53 $\mathrm{HU} /{ }^{\circ} \mathrm{C}$, soft $0.50 \mathrm{HU} /{ }^{\circ} \mathrm{C}$, detail $0.53 \mathrm{HU} /{ }^{\circ} \mathrm{C}$ ).

95\% (gray) and 50\% (black) confidence interval (CI) and coefficient of determination for fat, muscle and bone.

\section{Discussion}

For evaluating the sensitivity of main human tissues in CTbased thermometry, our study is one of the first integrating VMI. VMI proved suitable for CT-based thermometry and enable a higher temperature sensitivity (fat $8 \%$, muscle $24 \%$, bone $211 \%$ ) compared to conventional polychromatic 120 $\mathrm{kVp}$ measurements. In addition, with conventional polychromatic measurements, there are no parameters to influence the temperature sensitivity. Tan et al [12] in 2019 did not find any statistically significant difference in CT numbers with varied detection parameters for the same temperature 
fat
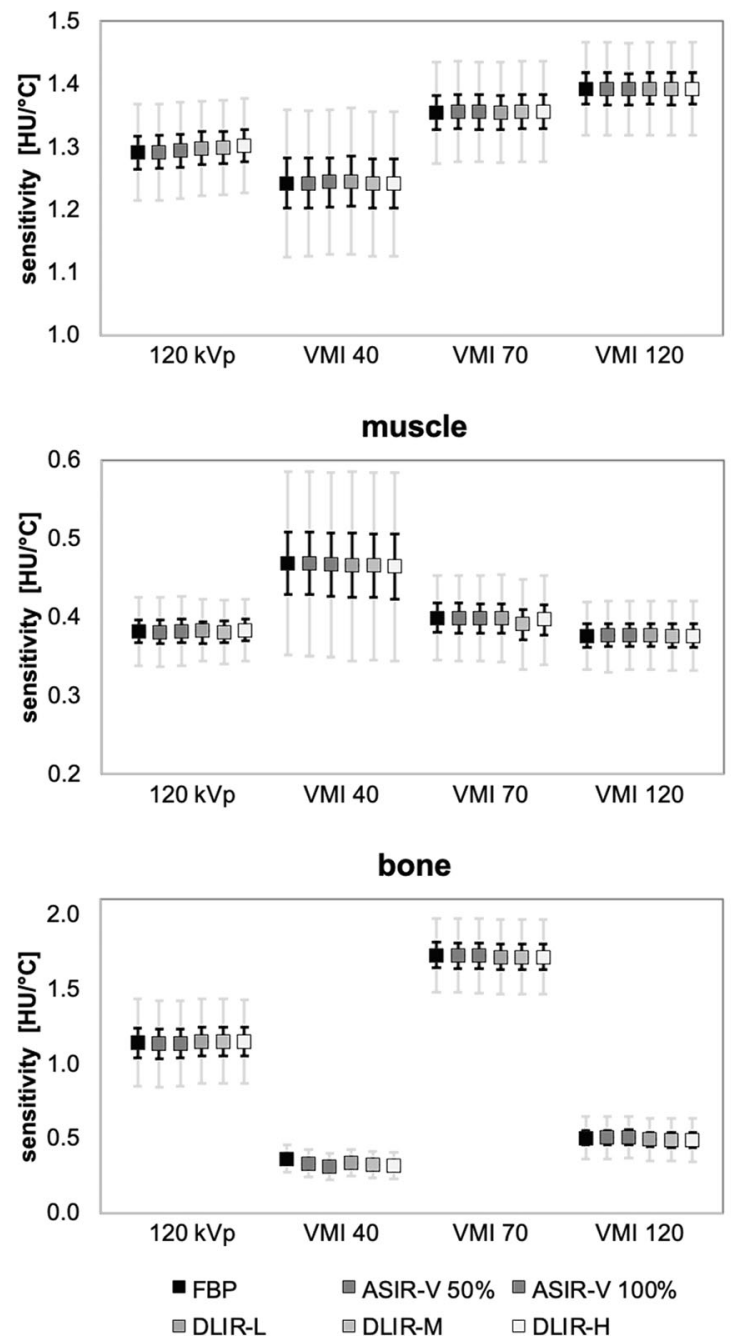

fat
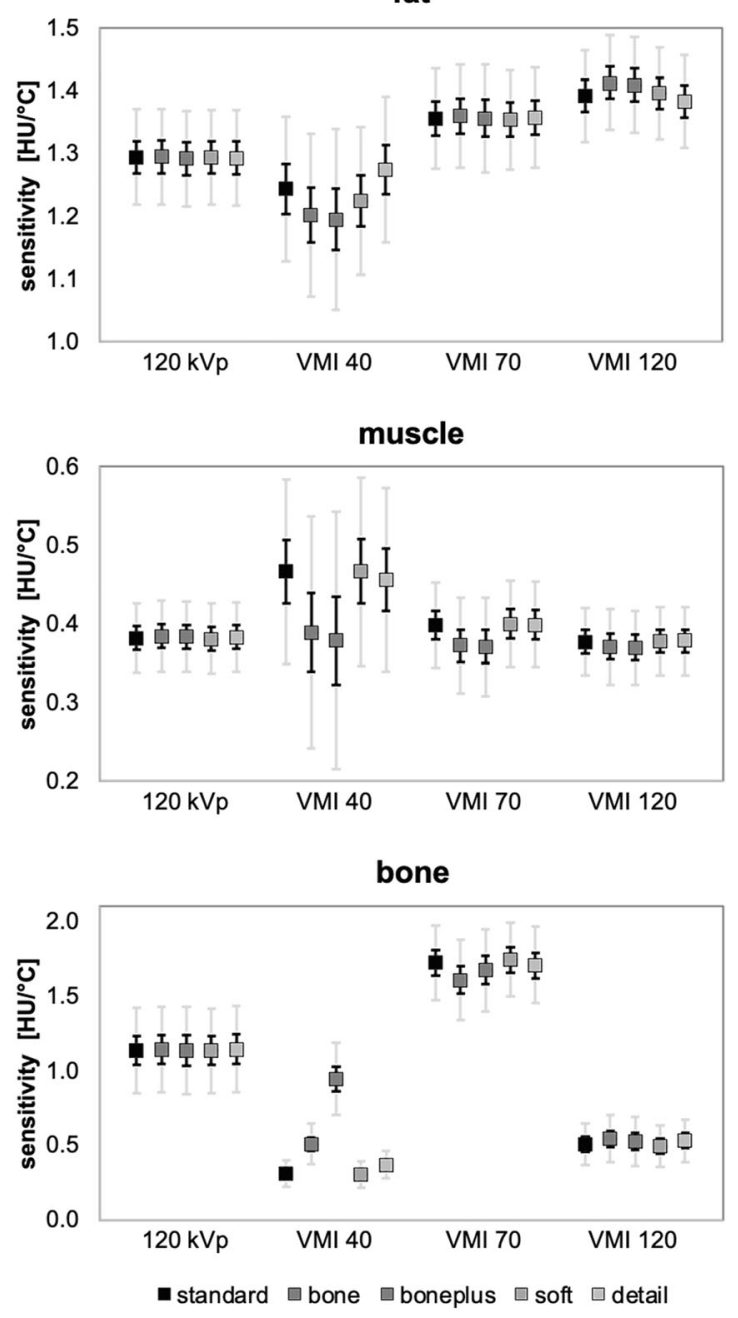

Fig. 5 Results of temperature sensitivity with 95\% (gray) and 50\% (black) confidence interval (CI) for left different reconstruction types (FBP, ASIR-V $50 \%$, ASIR-V 100\%, DLIR-L, DLIR-M, DLIR-H) and right different reconstruction kernels (standard, bone, boneplus, soft, detail).

setting, so that the scan parameters such as, e.g., voltage, tube current, pitch, gantry rotation time and slice thickness had no influence on the result of thermometry. With VMI, we found new parameters to modulate the temperature sensitivity. An interesting point is that, depending on the type of tissue, a certain monoenergy should be preferred (fat VMI at $140 \mathrm{keV}$, muscle VMI at $40 \mathrm{keV}$ and bone VMI at $50 \mathrm{keV}$ ). Furthermore, additional reconstructions can be obtained by dual-energy measurements. This leads to more detailed information about the material composition, e.g. material density images and data files (see Fig. 1 options). However, VMI partly shows larger fluctuation of CT numbers, due to a slightly larger CI for the temperature sensitivity (Fig. 4 right). One reason could be beam hardening artefacts of bone, which also affect the measurements of fat and muscle. Separate calibration curves, depending on the tissue and monoenergy of the VMI, are required.
For clinical use, CT-based thermometry benefits from modern reconstruction algorithms such as ASIR-V and DLIR, which can drastically reduce the radiation dose [14, 16]. These kinds of reconstruction algorithms and the modification of other protocol parameters have no negative influence on CT numbers [12, 14, 17]. However, ASIR-V and DLIR reconstruction methods can reduce beam hardening artefacts (e.g. of bones) and thus improve the result for CT-based thermometry. Furthermore, the image noise can be drastically reduced, allowing more stable $\mathrm{CT}$ numbers for smaller ROIs.

The DLIR setup currently just works with the standard kernel. In future, more kernels will be added for DLIR from manufacturer, which should provide clear statements to kernel influences on CT-based thermometry in further investigations. A major problem of CT-based thermometry is the reproducibility of the results [13]. For this reason, we obtained multiple measurements for our 
investigations. The numerous repetitions lead to very reliable and stable correlations between temperature and CT number. In clinical application of CT-based thermometry, a slice should be measured multiple times to average the CT numbers.

The measured temperature sensitivity for the muscleimitating salt-water solution corresponds to literature sources $[4,5]$. Fat density varies naturally between 0.90 and $0.97 \mathrm{~g} / \mathrm{cm}^{3}$ [23]. Therefore, the homogeneous beeswax (density $0.95 \mathrm{~g} / \mathrm{cm}^{3}$ ) is used as a homogeneous tissue equivalent to avoid influences due to density changes. We measure CT numbers between $-53 \mathrm{HU}$ and $-97 \mathrm{HU}$ for a temperature range from 18 to $50{ }^{\circ} \mathrm{C}$. Porcine fat tissue samples, as comparable biotic tissue, show CT numbers between -105 and $-135 \mathrm{HU}$ for a temperature range from 20 to $45{ }^{\circ} \mathrm{C}$ [24]. The measurements with beeswax are limited to $50^{\circ} \mathrm{C}$. Hot temperatures lead to rapid melting and faster changes in CT numbers than predicted by the linear regression (Fig. 4 left). Excluding the critical $50^{\circ} \mathrm{C}$ measurement, the temperature sensitivity is $1.02 \mathrm{HU} /{ }^{\circ} \mathrm{C}$ $(120 \mathrm{kVp})$ and $1.13 \mathrm{HU} /{ }^{\circ} \mathrm{C}$ (VMI at $140 \mathrm{keV}$ ) for fat. Thus, VMI perform $11 \%$ better compared to $120 \mathrm{kVp}$.

There are some limitations to the present study. One of the major limitations is that the experiments were performed on a tissue-equivalent phantom. For example, physiological processes (e.g. blood perfusion) may cause local alterations in data points due to thermal conductivity and heat redistribution. In addition, we could not heat the phantom above $50^{\circ} \mathrm{C}$, due to the melting point of beeswax. However, it is possible to use the linear regression shown in Fig. 4 to estimate the CT numbers at higher temperatures.

In conclusion, with the application of dual-energy and VMI, CT-based thermometry has parameters to influence and improve temperature sensitivity. Using ASIR-V and DLIR has no negative influence on the results, opening up the potential of drastic dose reductions. The temperatureregulating water circuit system enables reproducible measurements of CT numbers as a function of temperature, e.g. for bone, fat and muscle tissue equivalents. The developed setup is a groundwork for further research concerning complex test objects regarding CT-based thermometry.

Funding Open Access funding enabled and organized by Projekt DEAL.

\section{Declarations}

Guarantor The scientific guarantor of this publication is Andreas Heinrich.

Conflict of Interest The authors declare no competing interests.

Statistics and Biometry At least one of the authors (Andreas Heinrich) has significant statistical expertise.
Informed Consent Written informed consent was not required (phantom measurement).

Ethical Approval Institutional Review Board approval was not required (phantom measurement).

\section{Methodology \\ - prospective \\ - experimental \\ - performed at one institution}

Open Access This article is licensed under a Creative Commons Attribution 4.0 International License, which permits use, sharing, adaptation, distribution and reproduction in any medium or format, as long as you give appropriate credit to the original author(s) and the source, provide a link to the Creative Commons licence, and indicate if changes were made. The images or other third party material in this article are included in the article's Creative Commons licence, unless indicated otherwise in a credit line to the material. If material is not included in the article's Creative Commons licence and your intended use is not permitted by statutory regulation or exceeds the permitted use, you will need to obtain permission directly from the copyright holder. To view a copy of this licence, visit http://creativecommons.org/licenses/by/4.0/.

\section{References}

1. Fani F, Schena E, Saccomandi P, Silvestri S (2014) CT-based thermometry: an overview. Int J Hyperthermia 30:219-227

2. Schena E, Giurazza F, Massaroni C, Fong Y, Park JJ, Saccomandi $P$ (2017) Thermometry based on computed tomography images during microwave ablation: trials on ex vivo porcine liver. In: 2017 IEEE International Instrumentation and Measurement Technology Conference (I2MTC), pp 1-6

3. Paul J, Vogl TJ, Chacko A (2015) Dual energy computed tomography thermometry during hepatic microwave ablation in an exvivo porcine model. Phys Med 31:683-691

4. Jenne JW, Bahner M, Spoo J et al (1997) CT on-line monitoring of HIFU therapy. In: IEEE Ultrasonics Symposium Proceedings An International Symposium (Cat No97CH36118), vol 1372, pp $1377-1380$

5. Fallone BG, Moran PR, Podgorsak EB (1982) Noninvasive thermometry with a clinical x-ray CT scanner. Med Phys 9:715-721

6. Bruners P, Levit E, Penzkofer T et al (2010) Multi-slice computed tomography: a tool for non-invasive temperature measurement? Int J Hyperthermia 26:359-365

7. Pandeya GD, Klaessens JHGM, Greuter MJW et al (2011) Feasibility of computed tomography based thermometry during interstitial laser heating in bovine liver. Eur Radiol 21:1733-1738

8. Bruners P, Pandeya GD, Levit E et al (2012) CT-based temperature monitoring during hepatic RF ablation: feasibility in an animal model. Int J Hyperthermia 28:55-61

9. Schena E, Massaroni C, Giurazza F et al (2016) Feasibility assessment and analysis of thermal sensitivity of CT-thermometry during microwave ablation of ex vivo porcine kidneys. In: 2016 Nanotechnology for Instrumentation and Measurement (NANOfIM), pp 5-16

10. Ruiter SJS, Heerink WJ, de Jong KP (2019) Liver microwave ablation: a systematic review of various FDA-approved systems. Eur Radiol 29:4026-4035

11. Kokuryo D, Kumamoto E, Kuroda K (2020) Recent technological advancements in thermometry. Adv Drug Deliv Rev 163-164:19 39 
12. Tan D, Mohamad NA, Wong YH et al (2019) Experimental assessment on feasibility of computed tomography-based thermometry for radiofrequency ablation on tissue equivalent polyacrylamide phantom. Int J Hyperthermia 36:553-560

13. Pohlan J, Kress W, Hermann KG et al (2020) Computed tomography thermography for ablation zone prediction in microwave ablation and cryoablation: advantages and challenges in an ex vivo porcine liver model. J Comput Assist Tomogr 44:744-749

14. Fan J, Yue M, Melnyk R (2014) Benefits of ASiR-V reconstruction for reducing patient radiation dose and preserving diagnostic quality in CT exams. White paper, GE Healthcare

15. Kim HG, Lee H-J, Lee S-K, Kim HJ, Kim M-J (2017) Head CT: image quality improvement with ASIR-V using a reduced radiation dose protocol for children. Eur Radiol 27:3609-3617

16. Greffier J, Hamard A, Pereira F et al (2020) Image quality and dose reduction opportunity of deep learning image reconstruction algorithm for CT: a phantom study. Eur Radiol 30:3951-3959. https:// doi.org/10.1007/s00330-020-06724-w

17. JHsieh J, Liu E, Nett B, Tang J, Thibault JB, Sahney S (2019) A new era of image reconstruction: TrueFidelity ${ }^{\mathrm{TM}}$. Technical white paper on deep learning image reconstruction. GE Healthcare

18. Akagi M, Nakamura Y, Higaki T et al (2019) Deep learning reconstruction improves image quality of abdominal ultra-highresolution CT. Eur Radiol 29:6163-6171

19. Li J, Dong D, Fang M et al (2020) Dual-energy CT-based deep learning radiomics can improve lymph node metastasis risk prediction for gastric cancer. Eur Radiol 30:2324-2333
20. Rassouli N, Chalian H, Rajiah P, Dhanantwari A, Landeras L (2017) Assessment of 70-keV virtual monoenergetic spectral images in abdominal CT imaging: a comparison study to conventional polychromatic 120-kVp images. Abdom Radiol (NY) 42:25792586

21. Hubig M, Schenkl S, Muggenthaler H et al (2018) Fully automatic CT-histogram-based fat estimation in dead bodies. Int J Legal Med 132:563-577. https://doi.org/10.1007/s00414-017-1757-5

22. Schenkl S, Muggenthaler H, Hubig M et al (2017) Automatic CTbased finite element model generation for temperature-based death time estimation: feasibility study and sensitivity analysis. Int J Leg Med 131:699-712

23. Lochner S, Graw M (2015) Physikalische Eigenschaften menschlichen Weichgewebes. Vergleichende Untersuchung an Erwachsenen und Kindern. 10. gemeinsames Symposium der DGVP und DGVM am 5. und 6. September 2014 in München: S.83.

24. Weiss N, Sosna J, Goldberg SN, Azhari H (2014) Non-invasive temperature monitoring and hyperthermic injury onset detection using X-ray CT during HIFU thermal treatment in ex vivo fatty tissue. Int J Hyperthermia 30:119-125

Publisher's note Springer Nature remains neutral with regard to jurisdictional claims in published maps and institutional affiliations. 